\title{
Towards Very High Voltage SiC Power Devices
}

\author{
D. Planson ${ }^{\mathrm{a}}$, P. Brosselard ${ }^{\mathrm{a}}$, D. Tournier ${ }^{\mathrm{a}}$, L.V. Phung ${ }^{\mathrm{a}}$, C. Brylinski ${ }^{\mathrm{b}}$ \\ ${ }^{a}$ Université de Lyon, INSA de Lyon, CNRS UMR 5005, Ampere Laboratory, \\ 21, Avenue Jean Capelle, F-69621 Villeurbanne Cedex, FRANCE \\ ${ }^{\mathrm{b}}$ Université de Lyon, Université Lyon1, CNRS UMR 5615, \\ Laboratoire des Multimatériaux et Interfaces, \\ 43, Boulevard du 11 Novembre 1918, F-69100 Villeurbanne Cedex, FRANCE
}

The development of high voltage devices is a great challenge. At least, railway and high voltage distribution network are example of applications requiring high voltage devices. SiC power devices and technology seems to be mature enough to give a short term solution. Indeed, silicon carbide devices appear to be the semiconductor of choice for high voltage $(>6.5 \mathrm{kV})$ applications compared to Gallium Nitride and Diamond. For high voltage devices, periphery protection is mandatory in order to reduce the well-known electric field crowding taking place at the junction edge. Some details are given about the different periphery technics (JTE, guard rings, MESA) applied to SiC devices, before combining some of them to reach higher and higher breakdown voltages. Some works remaining to be done are given as a conclusion of this paper.

\section{Brief Introduction: the Motivations towards Silicon Carbide for Very High Voltage Devices}

Railway Applications

Silicon components are widely used in railway traction through IGBT with different voltage ranges $(1200,1700,3300$ and $6500 \mathrm{~V})$ depending on the applications (Tramway, regional and high speed trains). Most of the power flows through the power devices, but auxiliary systems become more and more important (heating, air conditioning system, lighting, communication and information...) and require an increasing volume in the coach. Downsizing the volume of the converter is now possible with the use of $1200 \mathrm{~V}$ $\mathrm{SiC}$ available unipolar devices (Schottky, JFETs and MOSFETs) by increasing the switching frequency, and hence decreasing the size of the passive components. These devices could also allow reducing the size of the cooling system due to smaller losses and better conduction of the heat thanks to SiC. 


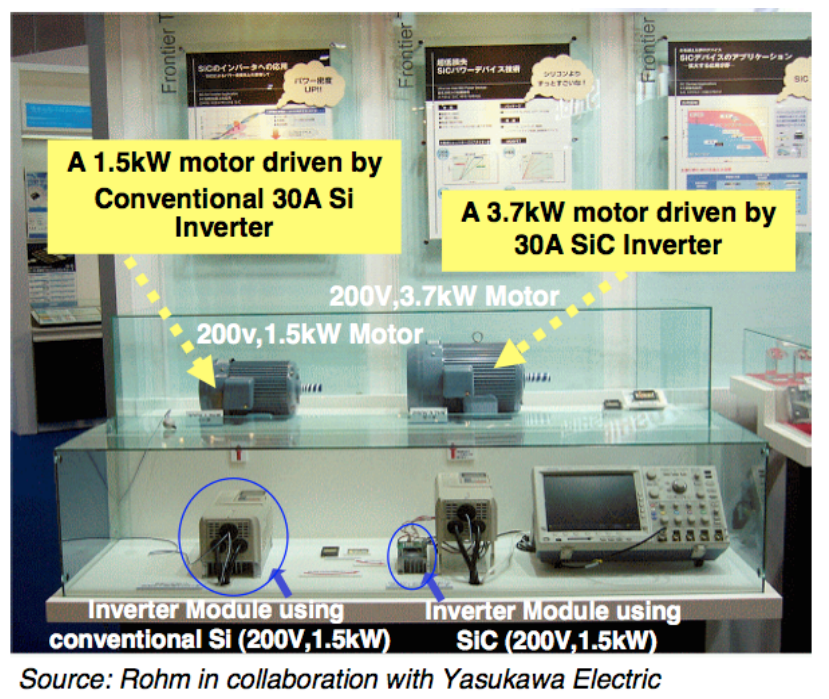

Figure 1: Illustration of benefit of WBG switches: $\mathrm{Si}$ and $\mathrm{SiC} 1.5 \mathrm{~kW}$ inverter volume comparison ( $\mathrm{SiC} / \mathrm{Si}$ power density ratio is about 20 ).

High voltage devices (more than $10 \mathrm{kV}$ ) are required for power supply chain. A heavy high voltage transformer decreases the supply voltage $(25 \mathrm{kV})$ down to a lower voltage to supply the $1500 \mathrm{~V}$ DC with the help of a rectifier. This transformer is heavy (more than 10 tons) and bulky (more than $50 \%$ of the locomotive). In order to replace it, research projects aim to develop an AC/DC converter with several stages (using between 12 and $18 \mathrm{Si}-\mathrm{IGBT} 6.5 \mathrm{kV}$ ). With the use of high voltage devices, this figure could be reduce by a factor of 2, allowing to split the converter in several parts and thus increasing the number of travelers in the train.

\section{$\underline{\text { Smart Grid Applications }}$}

With the arrival of renewable energy (Photovoltaic's and wind mills), the high-voltage distribution network is changing since the beginning of 2000. The European network is interconnected and long distance exchanges of energy are now a reality.

From the beginning up to now, the present solution uses AC high voltage. But the increasing distance (more than $100 \mathrm{~km}$ ) make the DC high voltage more profitable from the economic point of view due to the line losses. Moreover, the DC transport requires one conductor less. The very good yield of power electronic converters makes them attractive for $\mathrm{DC}$ transport of electricity. According to the prediction of major $\mathrm{T} \& \mathrm{D}$ actors (Alstom Grid, GE, ABB...), and as illustrated on figure 2, DC/DC converters are required with the following voltages $600 \mathrm{kV} / 150 \mathrm{kV}, 150 \mathrm{kV} / 50 \mathrm{kV}, 50 \mathrm{kV} / 10 \mathrm{kV}$ and finally $10 \mathrm{kV} / 500 \mathrm{~V}$. This is the reason for high voltage devices able to sustain at least 15 $\mathrm{kV}$. Smart grid applications are one of the major issues in this field to realize LCC (Line Commutated Converter) AC/DC converters. 


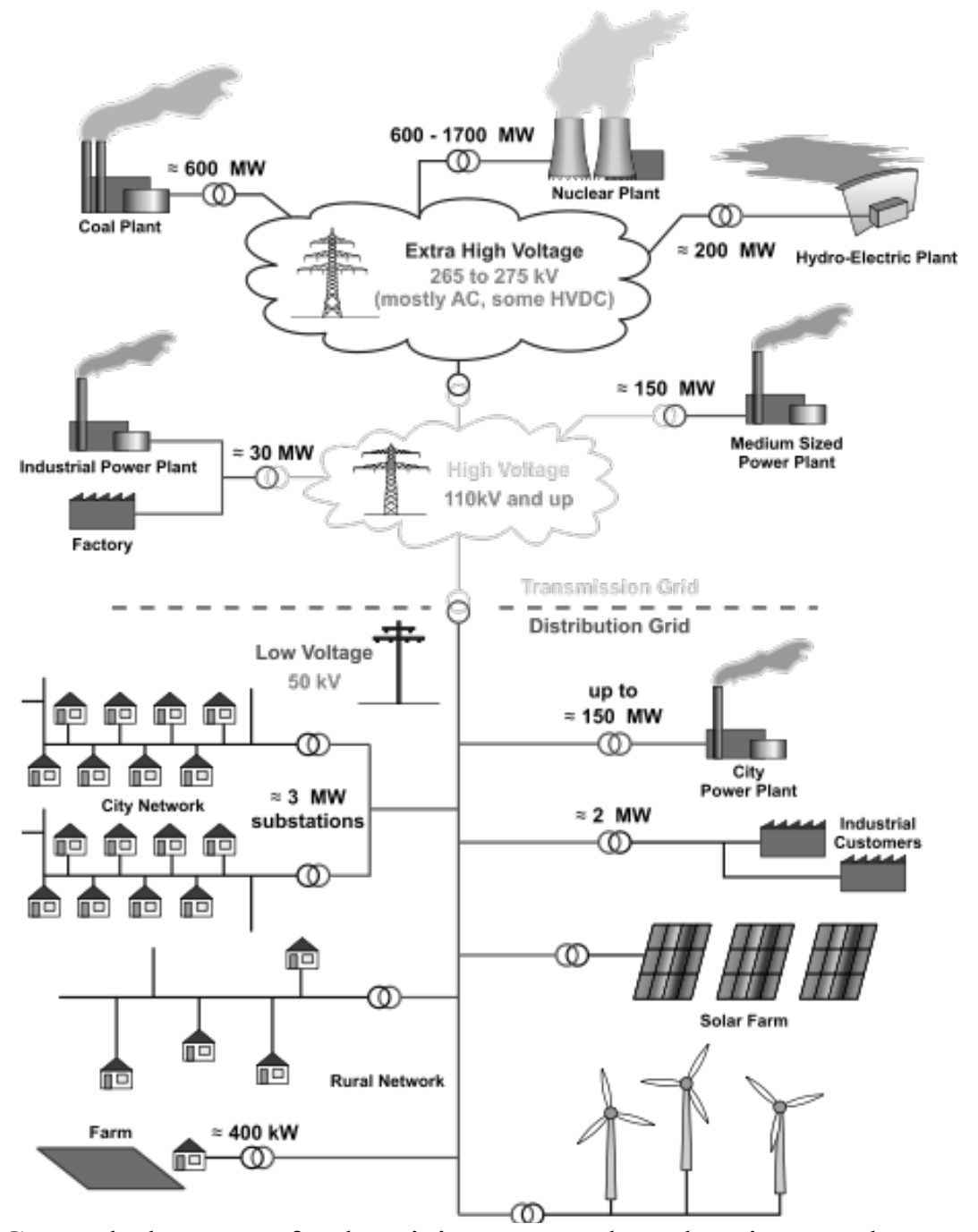

Figure 2: General layout of electricity networks showing end-user and source interconnection (Solar and Wind farms...) at distribution grid level.

Railway and renewable energy applications also require high voltage devices. Both high voltage $(>10 \mathrm{kV})$ and high current $(>1 \mathrm{kA})$ are required. GaN devices breakdown voltage limitation below $1 \mathrm{kV}$ is related to technological issues: no p-type doping, high quality bulk material nor thick epilayer are available. Concerning diamond, even if high voltage diamond diodes have been demonstrated [1], the substrates size dimensions $(4 \mathrm{~mm} \times$ $4 \mathrm{~mm}$ ) and the doping issues are also limiting their performances.

For such very high voltage devices, highly efficient periphery protections are needed. The next section will review the periphery protections technics applied to diodes and transistors. Recent results including MESA-JTE and MESA-JTE field rings combination will be given. 


\section{Periphery protections for Very High Voltage Silicon Carbide Devices}

High voltage devices are vertical ones where the current flows from one electrode at the top the other one at the backside. It allows to exploit the full thickness of the epilayer as a drift layer, which reduces the device' size compared to a lateral structure. It requires an important drift layer length with an optimal doping to match the trade-off between onresistance and breakdown voltage.

From a device design point of view, the realization of an effective edge termination is one of the biggest challenges. Many techniques like guards rings, floating field rings, JTE... are used to make the electric field uniform at the edge of the device. In the first part of this section, different periphery protections will be reviewed shortly, then a state of the art will be presented and finally the remaining works to reach high voltage devices will be drawn.

\section{$\underline{\text { Different periphery technics }}$}

Junction Termination Extension (JTE). This protection is very often used in SiC. This surrounding ring is realized with aluminum or a boron implantation with a controlled dose and requires an additional mask level.

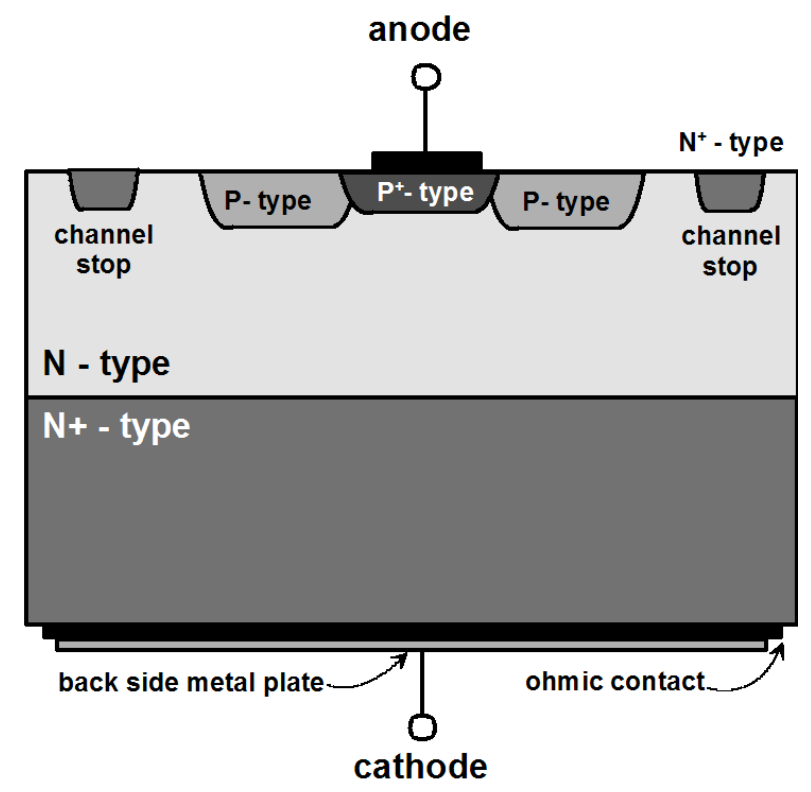

Figure 3: Schematic view of the PiN diode with a JTE termination and a channel stop.

When the device is reverse biased, the depletion layer spreads into the JTE. Once totally depleted, the JTE becomes a highly resistive area and the electric potential is distributed over the full length of the JTE.

The total dose of the JTE must be chosen properly so that it can be totally depleted before field crowding occurs either at the JTE end or at the intersection between $\mathrm{P}+$ and JTE zone. Three parameters define the JTE characteristics: first the JTE length must be optimized and then the breakdown voltage strongly depends on the JTE dose as it could be seen on Figure 4. When the dose is too high, the JTE protection has no effect and the 
breakdown voltage drops drastically, for a smaller dose, the maximum electric field peaks will have comparable height. The optimal dose is reached once the peaks have exactly the same magnitude.
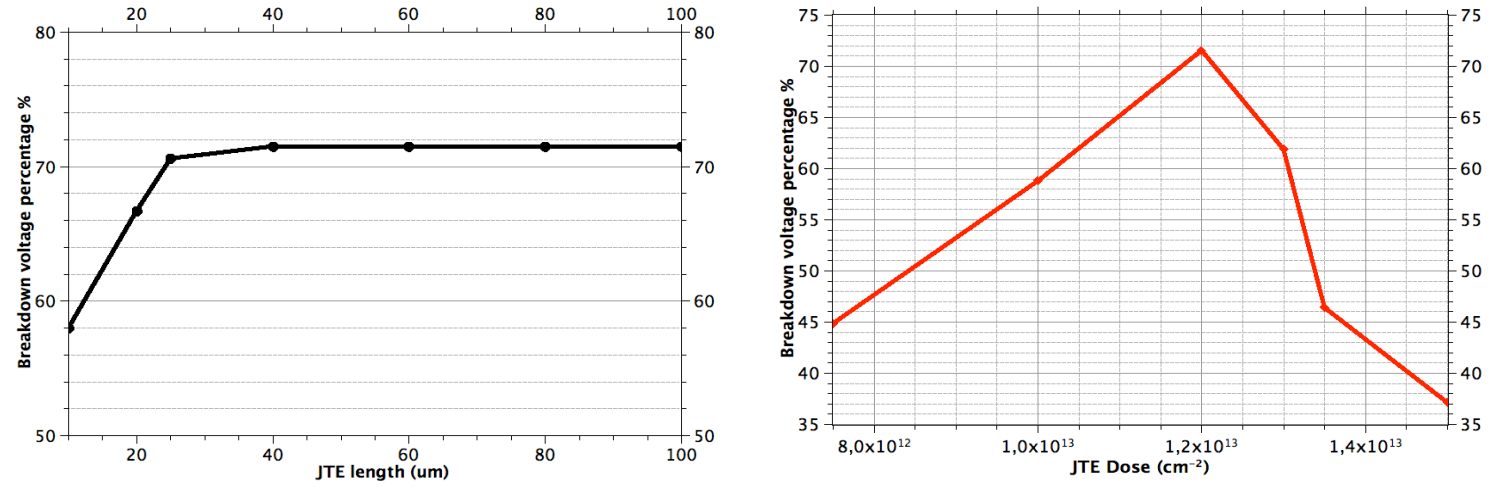

Figure 4 Influence of the JTE length (a) and dose (b) for a PiN diode with a JTE termination. The $y$-axis is a percentage of the breakdown voltage $\left(\mathrm{V}_{\mathrm{br}}\right)$ obtained from the ratio between the actual voltage and the ideal one.

Guard rings. These surrounding rings are realized in the same time as the main junction either with ion implantation or by VLS [2].

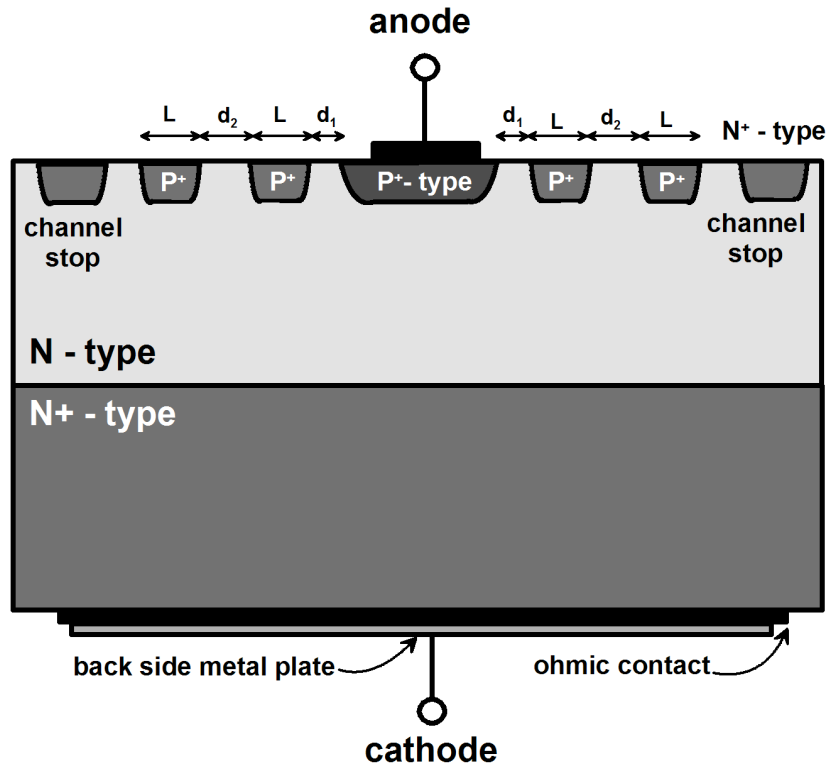

Figure 5: Schematic view of the PiN diode with a guard rings termination

The rings act as an equipotential spreader and hence decrease the electric field. Each ring is equipotential. The parameters to be optimized are the number of rings and the distance between them. 


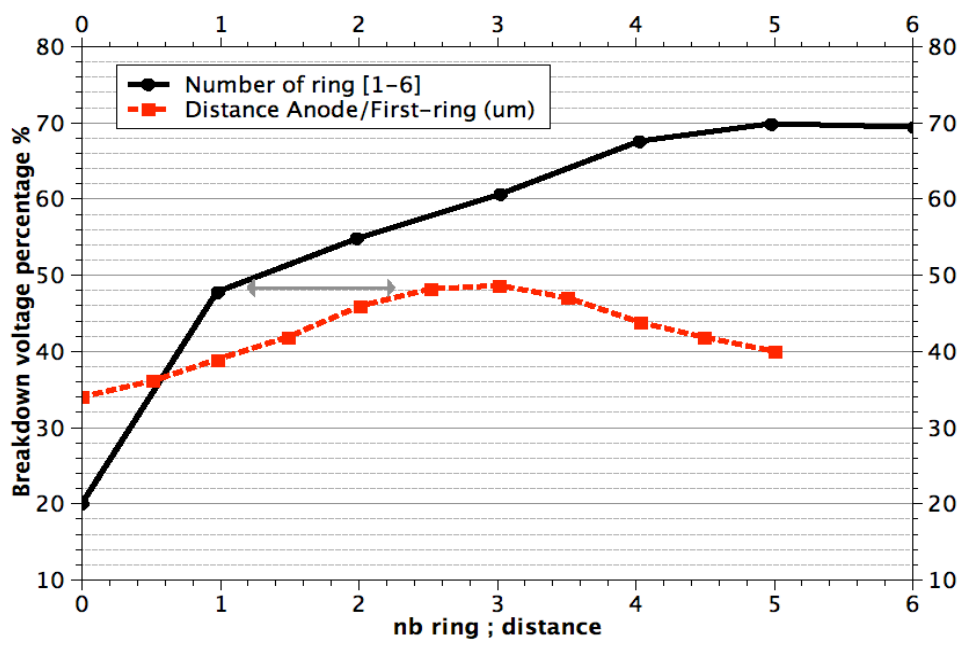

Figure 6: Breakdown voltage percentage versus the distance in between the anode and the first ring (red curve) and the optimized breakdown voltage versus the number of rings (black curve).

The breakdown voltage is very sensitive to the distance between the rings and these are getting smaller when the number is increased. Numerical simulations are mandatory to optimize the distance based on the electric field equilibrium at the border of each ring.

MESA: An etching process is used to remove the surrounding material at the periphery of the main junction. The breakdown voltage depends strongly on the etch depth, and for the high voltage device, this technique is often combined with a JTE, and is described as MESA-JTE as shown in Figure 7. The parameters to be optimized are the MESA etch depth, the JTE length and also the dose of the JTE.

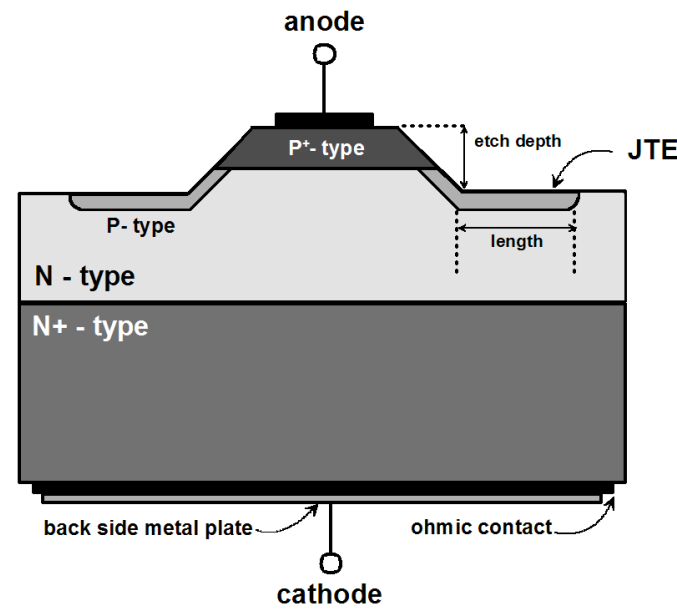

Figure 7. Schematic view of the PiN diode with a MESA-JTE termination. 


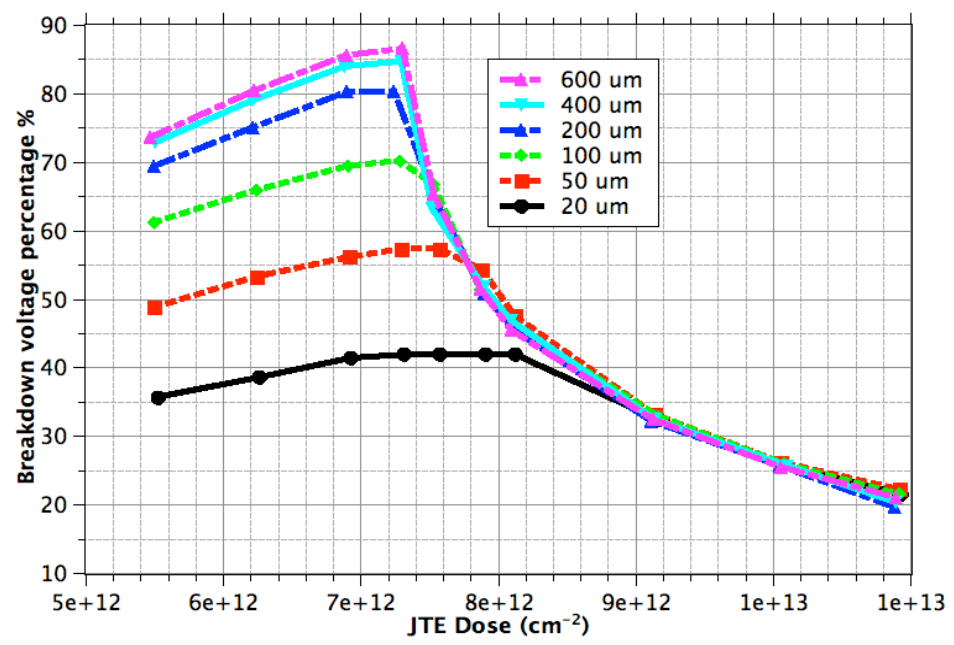

Figure 8. Breakdown voltage percentage of a MESA-JTE diode versus the implanted dose of the JTE for different JTE lengths.

For a dose of $7 \times 10^{12} \mathrm{~cm}^{-2}$, the breakdown voltage is closed to the ideal $\mathrm{P}^{+} \mathrm{N}$ plane semiinfinite junction $(16.5 \mathrm{kV})$ and is independent of the JTE length. When the etching depth increases the range of optimized dose also increases, and the protection efficiency increases. The combined MESA-JTE allows obtaining better results than MESA or JTE edge terminations.

Combination of different terminations: The advantages of each termination could be combined and adapted to the junction features, as an example, the etched JTE has been applied to the thyristor structure [3].

New protections are needed, using combination of MESA, single and/or multiple JTE, and guard rings [4] in order to increase the breakdown voltage. It allows widening the parameter ranges and being closer to the $100 \%$ efficiency, but one should keep in mind that the area used by the protection itself should be reduced as much as possible to reduce the total cost of the device. It is particularly true for high voltage device, due to the thick drift layer. 


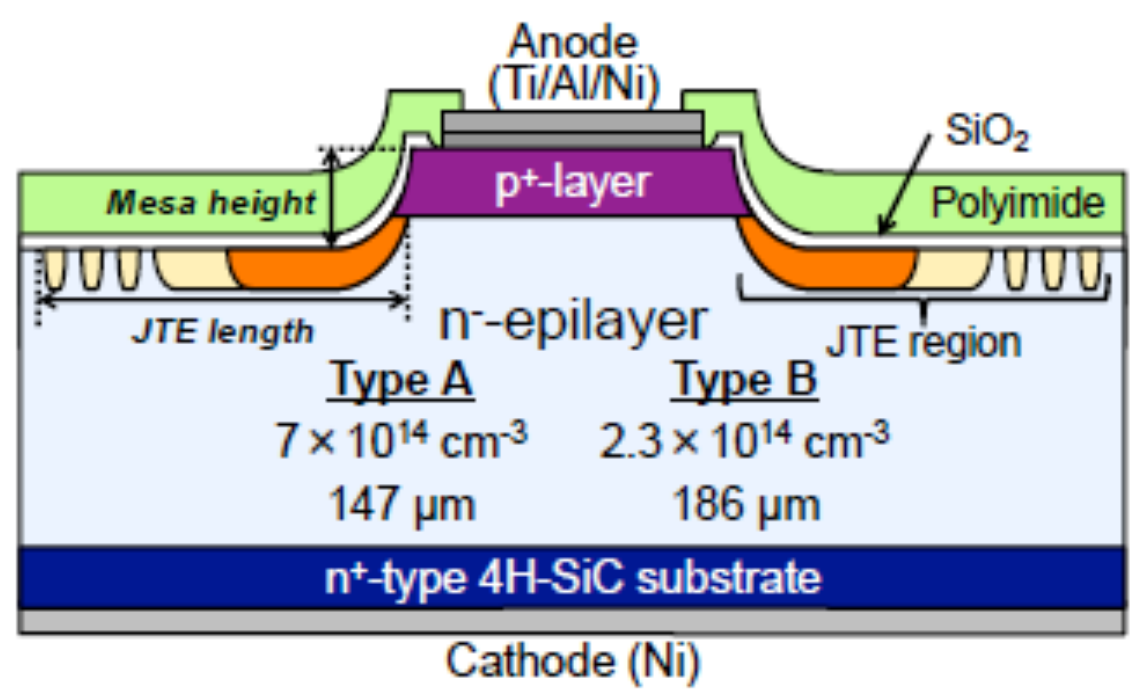

Figure 9. Schematic cross section of a $4 \mathrm{H}-\mathrm{SiC}$ PiN diode protected by two-zone JTE and space-modulated JTE [5].

Short state of the art

Even if unipolar diodes performances are theoretically lower than bipolar ones, the experimental performances are limited by carrier lifetime, ohmic and Schottky contact quality. Thus both JBS and bipolar high voltage diodes have been demonstrated.

\section{JBS Diodes.}

JBS and Single JTE (Junction Termination Extension) has been applied to $10 \mathrm{kV}-10 \mathrm{~A}$ and 20A JBS diode exhibiting a leakage current of $1 \mu \mathrm{A} @ 10 \mathrm{kV}$ [6].9 kV JBS have been protected with JTE assisted with field rings, and exhibit a relatively low leakage current of $100 \mu \mathrm{A} @ 10 \mathrm{kV}$ [7] and losses in comparison to 6.5kV Si-IGBT [8].

\section{Bipolar Diodes.}

Very high breakdown voltage has been demonstrated very recently, the world record being a $22 \mathrm{kV}$ bipolar diode [5] using a two-zone JTE combined with JTE-rings. Also a recent result with a shorter JTE length has been presented in [9] for a $10 \mathrm{kV}$ PiN diode.

\section{Transistors}

All kinds of transistors have been demonstrated with breakdown voltage higher than 9 $\mathrm{kV}$. Unipolar devices exhibit a large on-resistance with fast switching, contrary to the bipolar transistor depending on the minority carrier lifetime. Concerning unipolar switches, a $9 \mathrm{kV} \mathrm{JFET}$, protected by MESA/JTE has been fabricated [10], but a quite high gate bias $(-50 \mathrm{~V})$ is necessary to block the transistor. In order to achieve high voltage and high current applications requirements, i.e. to overcome the large resistance of high voltage unipolar devices, twelve $10 \mathrm{kV}$ MOSFETs have been connected in parallel with JBS diodes in the same module [11]. For bipolar devices, MESA/JTE protected BJT (Bipolar Junction Transistor) have shown a $10 \mathrm{kV}$ breakdown voltage, but the current gain is limited to 28 [12]. Etched JTE has been used to protect nearly $6 \mathrm{kV}$ thyristors to replace the commonly used implanted JTE [13]. 


\section{Works to be done for increasing the breakdown voltage}

The impact of the bend radius will also be shown by TCAD means.

The high voltage devices are usually used for high power applications, it means that increasing the area of the active part of the device is important. Rectangular shape of device is one way to increase the size in comparison with circular one. In such case, rounded corner are designed to avoid electric field crowding.
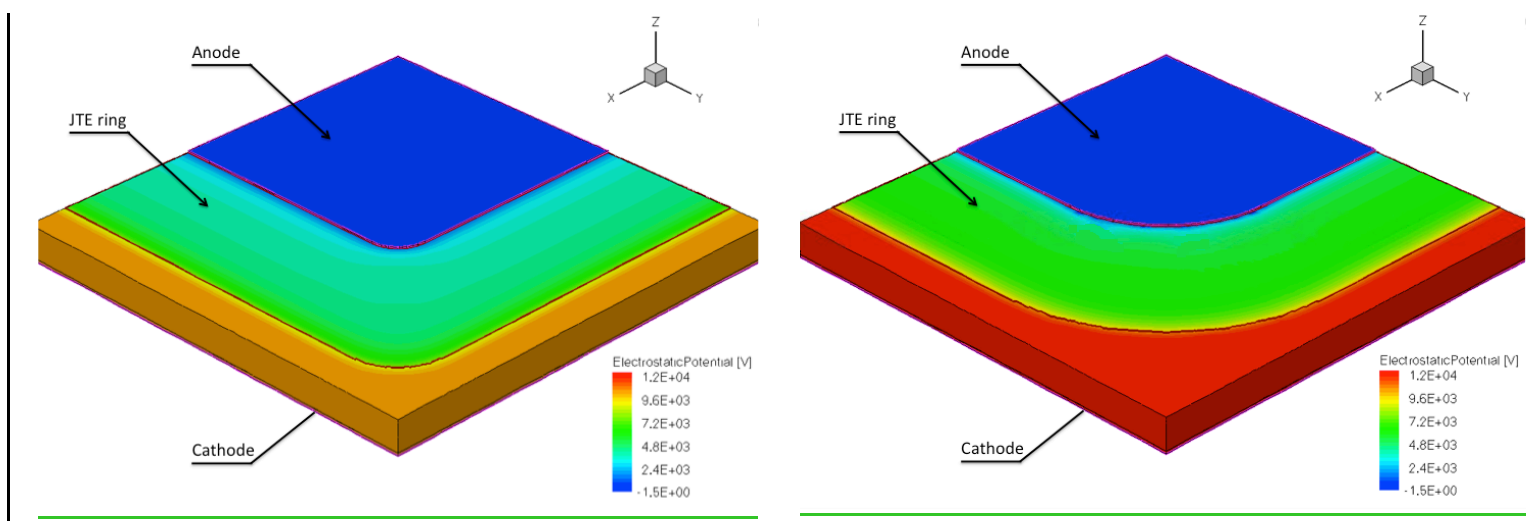

Figure 10. Equipotential line distribution at the rounded corner of a PiN diode for two bend radius $(120 \mu \mathrm{m}$ left and $450 \mu \mathrm{m}$ right).

A 3D-simulation has been performed to exhibit the effect of the bend radius on the maximum eùlectric field in the structure in Figure 10. The simulation was stopped for the same critical electric field in both structures. The bigger bend radius allows an increase on the breakdown voltage of $2 \mathrm{kV}$ compared to the smaller one allowing an increase in JTE efficiency from $66 \%$ up to $80 \%$.

\section{UV-switching devices}

In the perspective of high voltage converter, a demonstration of UV-switching devices operation has been developed using a UV-LED light triggered thyristors (LTT) [14]. These were protected with an etched guard ring assisted JTE, with 6 rings as we can see on Figure 11. 


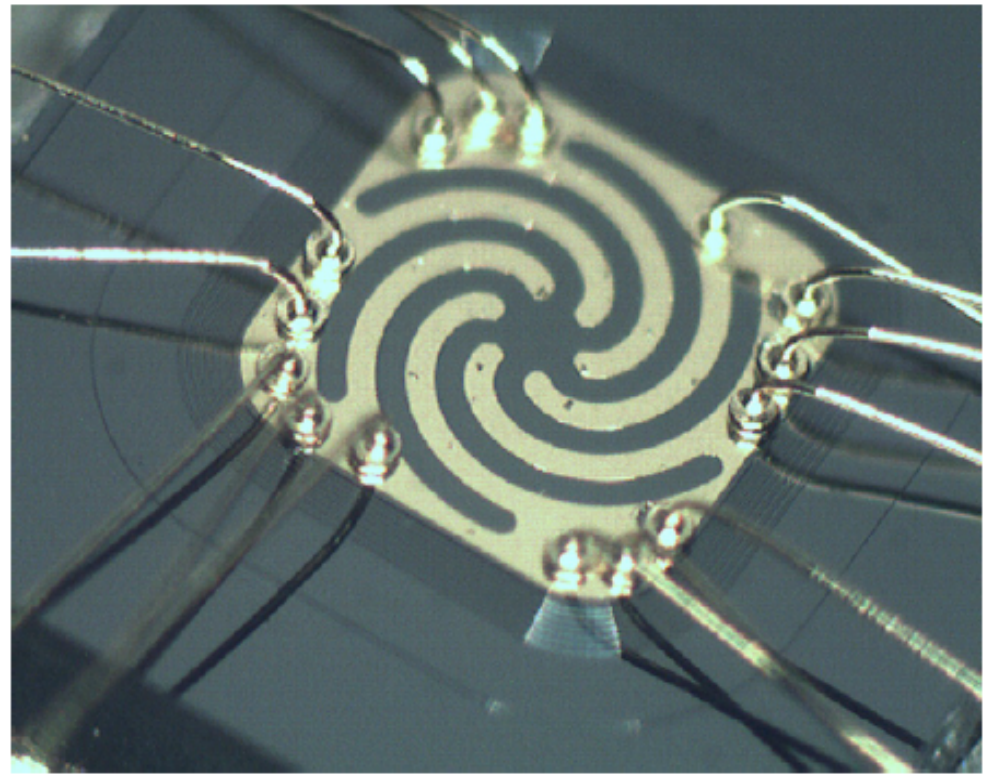

Figure 11. Schematic of the experiment of the serial association of two thyristors.

The advantages of the light triggered thyristor (LTT) are the galvanic isolation of the driver and the reduction of EMI interferences, which are interesting for high voltage systems. In systems requiring very high voltage, such as HVDC transmission that works at several hundred of $\mathrm{kV}$, serial association of semiconductor devices will be needed, even when using SiC ones.

The schematic of the circuit is shown on Figure 12. The DC bus voltage was set as an example to $300 \mathrm{~V}$ and the load was a $235 \Omega$ resistor.

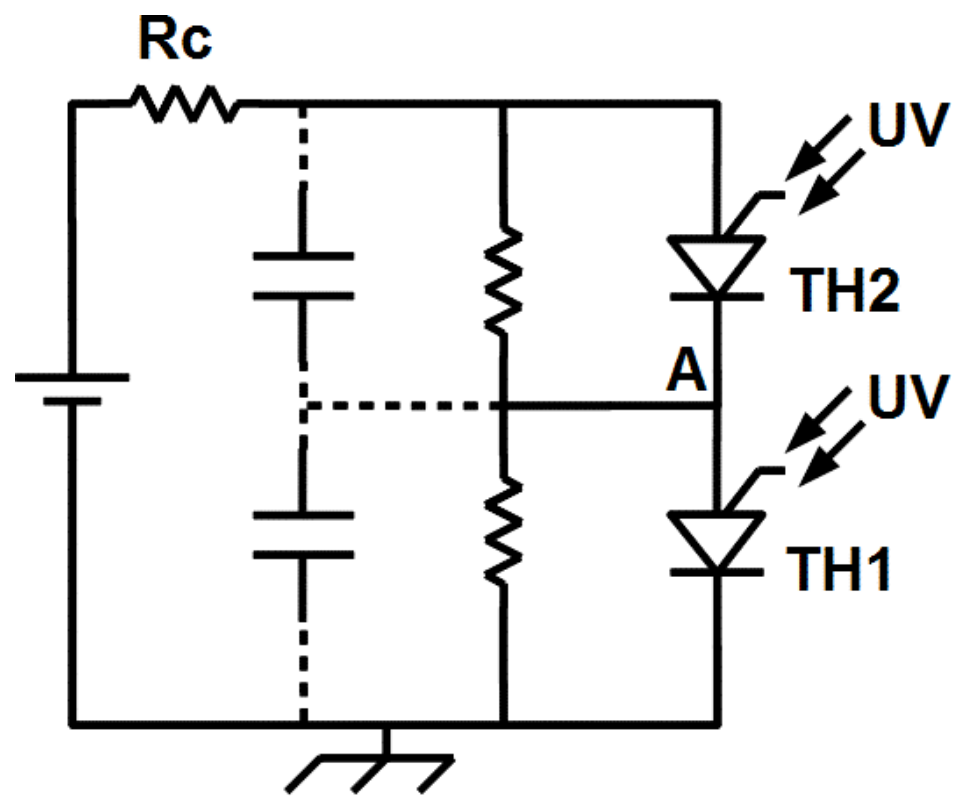

Figure 12. Schematic of the experiment of the serial association of two thyristors.

The experimental setup is shown on figure below. 


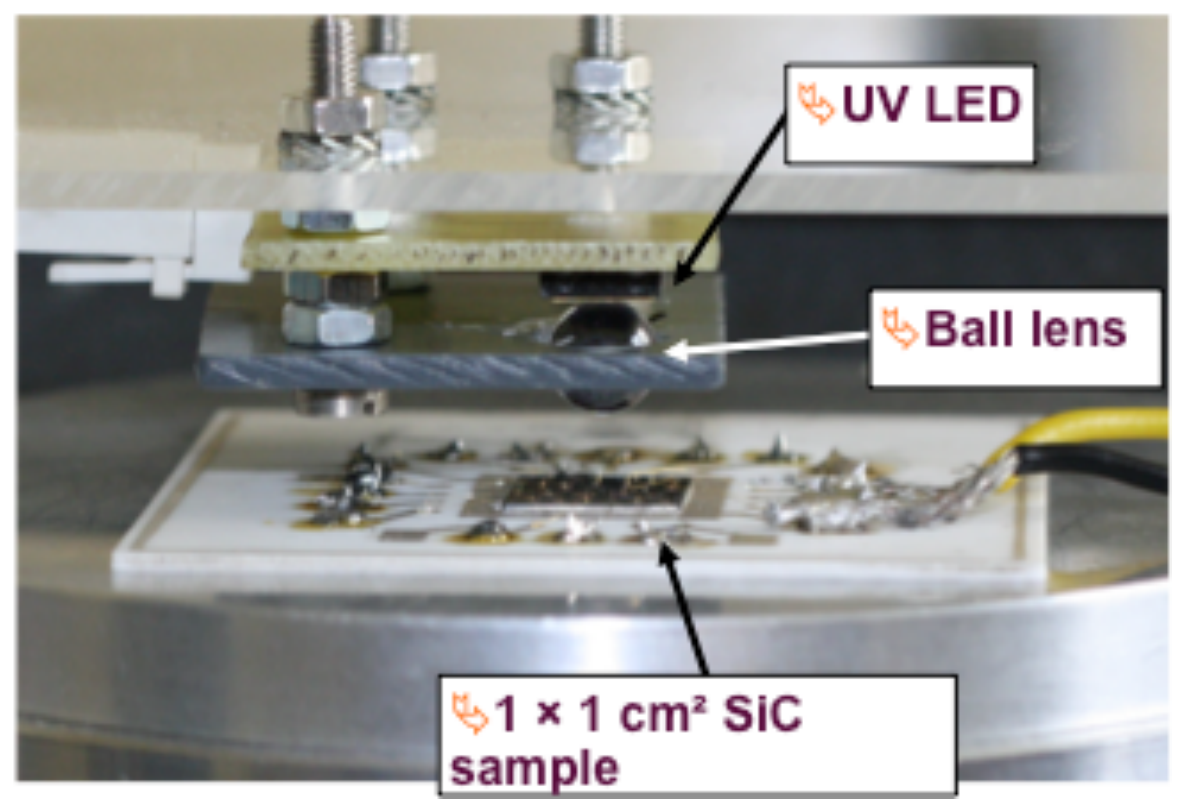

Figure 13. Experimental setup for the optical thyristors, attached on alumina substrate and wire bonded.

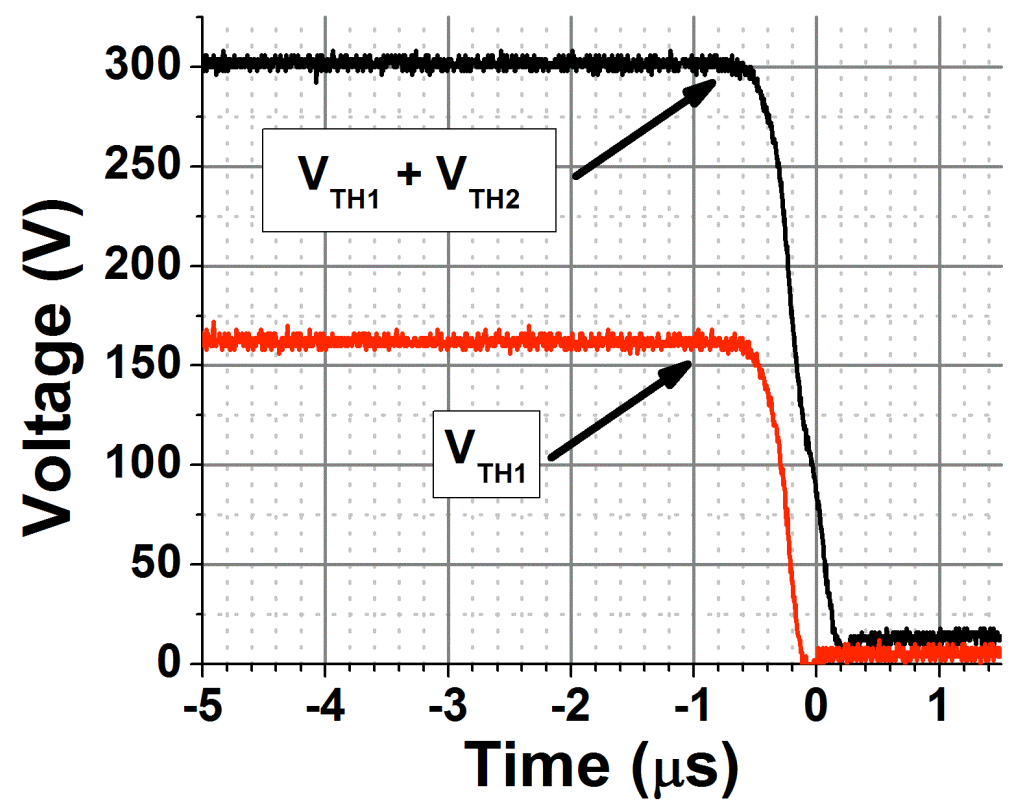

Figure 14. Serial association of two thyristors with balancing capacitors: TH1 voltage and sum of the $\mathrm{TH} 1$ and $\mathrm{TH} 2$ voltages during the commutation.

The voltages of the thyristors during the switching with balancing capacitors of $22 \mathrm{nF}$ is shown in the Figure 14. The voltage between the two thyristors is then equally shared. However the fall time is longer and around 500 ns against $200 \mathrm{~ns}$ without the capacitors, and the switching losses are therefore higher.

\section{Passivation layers}

Higher voltage devices will induce a high electric field stress in the passivation layer. Therefore, extended performances of packaging materials are necessary to sustain higher 
voltage and also temperature. An insulation material with appropriate high dielectric rigidity will prevent the formation of premature arcing. Polyimides appear as potential candidates for this passivation layer [15].

\section{Packaging}

Specific packages are required for high voltage devices. The material itself must be able to sustain high electric field, but the layout of the electrodes must be properly designed (distance between electrodes).

\section{References}

1. P.N. Volpe, P. Muret, J. Pernot, F. Omnes, T. Teraji, Y. Koide, F. Jomard, D. Planson, P. Brosselard, N. Dheilly, B. Vergne, S. Scharnolz. Appl. Phys. Lett. 97, $223501(2010)$

2. D. Carole, S. Berckmans, A. Vo-Ha, M. Lazar, D. Tournier, P. Brosselard, V. Soulière, L. Auvray, G. Ferro, C. Brylinski. In Materials Science Forum, volume 717-720, pages 169-172. Trans Tech Publ, 2012.

3. G. Pâques, N. Dheilly, D. Planson, R. W. De Doncker, S. Scharnholz. In Materials Science Forum, Vol. 679-680, pages 457-460. Trans Tech Publ, 2011.

4. G. Feng, J. Suda, T. Kimoto. IEEE Electron Devices Transactions on, Vol. 59, pp.414-418, 2012.

5. H. Niwa, G. Feng, J. Suda, T. Kimoto. In Power Semiconductor Devices and ICs, 2012. ISPSD'12. Proceedings of the 24th International Symposium on, pages 381-384. IEEE, 2012

6. B.A. Hull, J.J. Sumakeris, M.J. O'Loughlin, Z. Qingchun, J. Richmond, A.R. Powell, E.A. Imhoff, K.D. Hobart, A. Rivera-Lopez, A.R. Hefner. Electron Devices, IEEE Transactions on, 55(8) :1864-1870, 2008

7. M. Berthou. "Implementation of high voltage Silicon Carbide rectifiers and switches ». PhD thesis, INSA de Lyon, 2012.

8. G. Wang, X. Huang, J. Wang, T. Zhao, S. Bhattacharya. in Solid-State Transformer application, Energy Conversion Congress and Exposition (ECCE), 2010 IEEE, pp.100-104,

9. T. Hiyoshi, T. Hori, J. Suda, T. Kimoto. In Materials Science Forum, volume 600, pages 995-998. Trans Tech Publ, 2009.

10. V. Veliadis, E.J. Stewart, H. Hearne, T. McNutt, W. Chang, M. Snook, A.J. Lelis, C.J. Scozzie. In Materials Science Forum, volume 679, pages 617-620. Trans Tech Publ, 2011.

11. M.K. Das, C. Capell, D.E. Grider, R. Raju, M. Schutten, J. Nasadoski, S. Leslie, J. Ostop, A. Hefner. In Energy Conversion Congress and Exposition (ECCE), 2011 IEEE, pp. 2689-2692, 17-22 Sept. 2011

12. Q.C. Zhang, R. Callanan, A.K. Agarwal, A.A. Burk, M.J. O'Loughlin, J.W. Palmour, C. J. Scozzie. In Materials Science Forum, volume 645, pages 10251028. Trans Tech Publ, 2010.

13. G. Pâques, S. Scharnholz, N. Dheilly, D. Planson, R.W. De Doncker. In Materials Science Forum, volume 717-720, pages 1167-1170. Trans Tech Publ, 2012.

14. N. Dheilly, G. Pâques, S. Scharnholz, P. Bevilacqua, C. Raynaud, D.-M. Nguyen, R.W. De Doncker, D. Planso n. In Electronics Letters, Vol 47, pp. 459-460

15. S. Diaham, M.L. Locatelli, T. Lebey, C. Raynaud, M. Lazar, H. Vang, D. Planson. In Materials Science Forum, Vol. 615-617 (2009) p. 695-698 